\title{
Biblioteca de Andalucia, contenedor y referente cultural autonómico
}

Tras la promulgación de la Ley 8/1983, de Bibliotecas, el Parlamento de Andalucía aprobó que Granada fuese la sede de la Biblioteca de Andalucia (en adelante BA). Su primera ubicación fue el Colegio de Niñas Nobles, propiedad de la Diputación Provincial y entonces en plena restauración. Una vez regulado su desarrollo durante 1987, al año siguiente se pone en marcha su instalación, se constituye un fondo de unos 50.000 volúmenes procedentes del Depósito Legal, y finalmente se inaugura en abril de 1990. En 1994 comienza una nueva etapa, en su segunda sede provisional, ahora compartiendo edificio con la Biblioteca Pública del Estado en Granada, de titularidad estatal.

La BA está considerada como biblioteca central ("cabecera") del Sistema, según la nueva Ley 16/2003, que también la convierte en garante de la recogida y conservación del patrimonio bibliográfico andaluz y de la difusión del mismo de forma presencial o remota, además de nodo de las dos redes básicas del Sistema, la de bibliotecas públicas, a la que eventualmente pueden sumarse las escolares, y la de centros de documentación y bibliotecas especializadas, con la posibilidad de asociación con universitarias, por lo que la BA, además de las clásicas funciones de conservación y difusión de fondos de o sobre Andalucía, asume la normalización bibliográfica y la cooperación interbibliotecaria.

La mayor parte de los fondos de la BA proceden del Depósito Legal, disposición administrativa que obliga a impresores, editores y productores a entregar un número determinado de ejemplares de toda clase de impresos y materiales audiovisuales, reproducidos en forma múltiple y destinados a la difusión, ya sea gratuita o no. De ahi que la colección más importante de la Biblioteca sea la que se recoge por este mecanismo, más del $50 \%$ del total de los fondos. También se recogen las obras publicadas en cualquier soporte sobre temática andaluza o de autores andaluces, editadas fuera de nuestra Comunidad, o anteriores a la constitución del Depósito Legal, que ingresan en la Biblioteca mediante adquisición o donación.

Entre estos fondos se encuentran más de 2.000 publicaciones oficiales de la Junta de Andalucia, la colección de préstamo domiciliario, la prensa andaluza digitalizada y colecciones de materiales como mapas y planos, incluyendo la colección de cartografía histórica desde el siglo XVI a 1930

El fondo más destacable es el de Luis Rosales, compuesto por 17.000 volúmenes, interesante por su valor y por su contenido bibliofilico. Algunas obras relevantes son la de Pedro de Aguilar, Tratado de la Caballería a la Jineta, de 1572 o la Nobleza de Andalucía, de Gonzalo Argote de Molina, también del siglo XVI. Obras dedicadas de Lorca, como el primer Romancero gitano, o la Oda a Walt Whitman. También con dedicatoria, obras de Alberti ilustradas con sus dibujos, de Juan Ramón Jiménez, Salinas, o revistas completas, como Cruz y Raya, Revista de Occidente, Cuadernos Hispanoamericanos, y otras posteriores como Escorial, Ciclón y Caballo Griego para la Poesía.

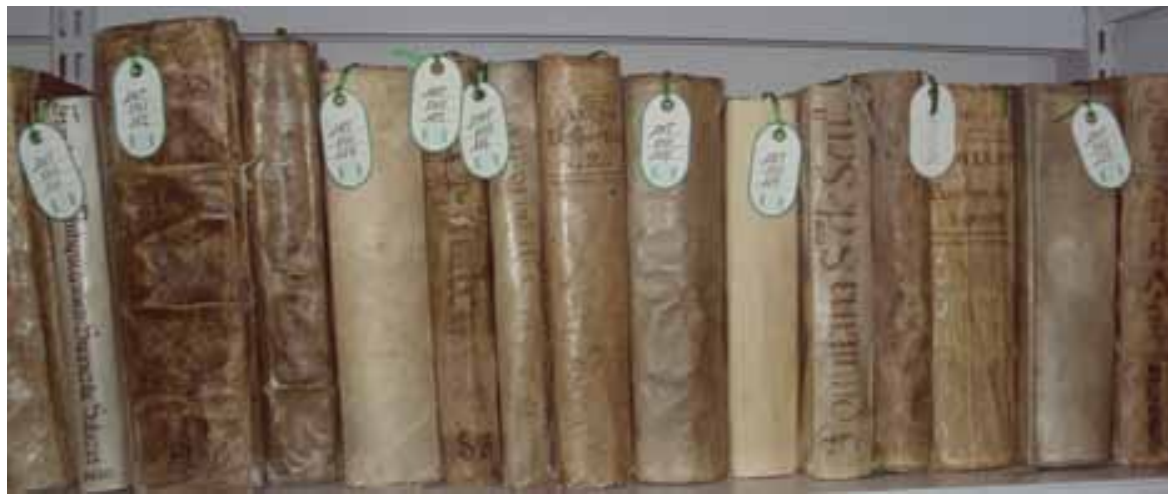

Fondo antiguo. Foto: Nadia Vitone/Isabel Bellido

El fondo de José Luis Cano, critico y poeta algecireño, más reducido que el anterior, desde el punto de vista literario supone una gran selección, incluyendo la Antología rota, de León Felipe, edición de 1947, o Las cosas del campo, de Muñoz Rojas, publicada en 1953 y revistas como La Torre (Puerto Rico), Realidad y Sur (Buenos Aires) y Cuadernos Americanos (México).

Junto a estas colecciones cedidas en los años 90, ahora la BA vuelve a recibir por adquisición o cesión de sus titulares varias colecciones interesantes, como el fondo Nicolás López, centrado en la figura de Ángel Ganivet. Con carácter de donación pura, se ha recibido durante 2009 la colección Rodríguez-Spiteri, compuesta por unos 600 títulos de tema malagueño, destacando el conjunto correspondiente a literatura gris y monografias del siglo XIX, que muestra la actividad económica, religiosa, institucional y cultural de la ciudad de Málaga y de su provincia.

La historiadora granadina Antonina Rodrigo, junto con su pareja, el anarquista catalán Eduardo Pons Prades, coleccionaron un importante legado especializado en Guerra Civil y posguerra, maquis, feminismo y anarquismo, con bastantes publicaciones extranjeras, especialmente francesas, como la Revue d'histoire de la deuxiéme Guerre Mundiale y el BuIletin del Centre de Recherches Hispaniques. Incorporado también a la BA durante 2008 y 2009, incluye los monográficos de Papeles de Son Armadans, con dedicatoria autógrafa de muchos de los autores, y la revista homónima fundada por Camilo José Cela.

$D^{a}$ Joaquina Albarracín ha donado también un lote de obras de temas arabistas, sobre España y el Magreb, como The moriscos of Spain. Their conversion and expulsion, por Henry Charles Lea, de 1901. Por su parte, la viuda del profesor Fórneas cede una importantísima colección de obras en distintos idiomas, especialmente árabe, fruto de su trayectoria universitaria, que completan la colección de fondos interculturales de la BA.

Respecto a los fondos adquiridos por la Biblioteca, el más antiguo es un incunable de 1478, las Obras completas de Séneca; manuscritos, como la curiosa publicación confeccionada en Córdoba en 1529, que recoge la regla de la Hermandad de Beneficiarios de la Universidad de Córdoba. Además, la BA ha adquirido en reproducción facsímil algunas obras de interés como el Codex Granatensis, completando de esta forma la colección de originales.

Otras obras coleccionadas durante estos 20 años son el manuscrito de Hurtado de Mendoza Guerras de Granada, uno de los 35 conocidos; el Idearium, revista de Ganivet en Granada, incluyendo los 15 primeros números; el Libro en que se anotan las labores del Real Hospicio de Granada; el Album de tipos y costumbres andaluzas; el Cancionero de Sevilla, Flores, artes, amores, o la obra de A. Calvert, Moorish remains in Spain... hasta completar un respetable número de obras, más de 6.000 , que constituyen el fondo antiguo de la BA, ya prácticamente digitalizado en su totalidad.

Gracias a la anteriormente descrita riqueza de fondos, la BA inició hace algunos años la edición de catálogos temáticos, representativos de sus fondos, hasta llegar a los diez ya editados, desde el dedicado a García Lorca hasta los más recientes sobre Machado y el Exilio. Junto a esta serie, por su propia naturaleza, la BA edita manuales de procedimiento para la Red de Bibliotecas Públicas, sobre procesos técnicos de materiales o diferentes operaciones catalográficas, clasificatorias y biblioteconómicas en general, el Boletín de Depósito Legal de Andalucía, el Catálogo Colectivo del Patrimonio Bibliográfico Andaluz, la Colección de Cartografía Histórica, la obra Fuentes de información sobre Andalucia, Los Quijotes de Órgiva y, finalmente, la coedición Cultura oral en la provincia de Granada y el primero de sus cuadernos didácticos.

Las lineas de trabajo de la BA en los últimos años, como órgano incardinado en la Dirección General del Libro, dirigidas fundamentalmente a la coordinación técnica de programas como la Biblioteca Virtual de Andalucia, las Bibliotecas Interculturales, Biblioteca Responde o asistencia técnica la automatización de la Red, actualmente se han visto diversificadas por la participación en acciones de dinamización lectora, a su vez facilitada por la creación de un nuevo Departamento de Difusión, cuya proliferación está permitiendo, en colaboración con otros centros culturales, convertir a la BA en un contenedor y referente cultural para Granada y toda la Comunidad Autónoma de Andalucia.

\section{Francisco Javier Álvarez García}

Director de la Biblioteca de Andalucia 